Analitika: Jurnal Magister Psikologi UMA, Vol. 12 (1) Juni (2020)

ISSN: 2085-6601 (Print), ISSN: 2502-4590 (Online)

DOI: http://dx.doi.org/analitika.v11i1.3498

\title{
ANALITIKA
}

Jurnal Magister Psikologi UMA

Available online http://ojs.uma.ac.id/index.php/analitika

\section{Hubungan antara Self Efficacy dengan Self Regulated Learning pada Mahasiswa yang Bekerja di Universitas Medan Area}

\section{Correlation between Self Efficacy with Self Regulated Learning on Working Students in University Medan Area}

\author{
Candra Wijaya1), Nurmaida Irawani Siregar ${ }^{2)^{*}}$ \& Hidayat $^{3)}$ \\ 1) Program Studi Manajenem Pendidikan Islam, Fakultas Ilmu Tarbiyah dan Keguruan, \\ Universitas Islam Sumatera Utara, Indonesia \\ 2) Program Studi Ilmu Psikologi, Fakultas Psikologi, Universitas Medan Area, Indonesia \\ 3) Program Studi Pendidikan Agama Islam, Fakultas Agama Islam, Universitas Muhammadiyah \\ Sumatera Utara, Indonesia
}

Diterima: 13 Februari 2020, disetujui: 27 Juni 2020, dipublish: 30 Juni 2020

*Corresponding author: E-mail: nurmaida.irawani@gmail.com

\begin{abstract}
Abstrak
Penelitian ini bertujuan melihat hubungan antara self efficacy dengan self regulated learning pada mahasiswa yang bekerja. Dimana yang menjadi subjek penelitian adalah mahasiswa yang bekerja di Universitas Medan Area yang memenuhi kriteria sampel dengan sampel sebanyak 67 mahasiswa. Hipotesis yang diajukan dalam penelitian ini adalah bahwa terdapat hubungan positif antara self efficacy dengan self regulated learning mahasiswa yang bekerja di Universitas Medan Area. Diperoleh hasil bahwa terdapat hubungan positif yang signifikan antara self efficacy dengan self regulated learning mahasiswa yang bekerja di Universitas Medan Area. Selain itu dari penelitian ini diketahui bahwa secara umum para mahasiswa yang bekerja di Universitas Medan Area memiliki self efficacy yang tergolong sedang dan self regulated learning yang juga tergolong sedang.

Kata kunci: Self Efficacy; Self Regulated Learning; Mahasiswa yang Bekerja
\end{abstract}

\begin{abstract}
The aim of thin research concern about the correlation between self efficacy with self regulated learning on the college students that working of University Medan Area. In this case, as the subject of thin research are the collage students that working of University Medan Area. The college students that working that fulfill the sampel of the criteria are 67 college students. The hypothesis that submitted in this research is that a positive correlation between self efficacy with self regulated learning on the collage students that working of University Medan Area. Based on the data analysis by using the Product Moment Metode Analysis as the result, there is the positive relationship that significant between self efficacy with self regulated learning on the collage students that working of University Medan Area.
\end{abstract}

Keywords: Self Efficacy; Self Regulated Learning; Working Students

How to Cite: Wijaya, C., Nurmaida, I.S., \& Hidayat. (2020). Hubungan antara Self Efficacy dengan Self Regulated Learning pada Mahasiswa yang Bekerja di Universitas Medan Area. Analitika: Jurnal Magister Psikologi UMA, 12 (1): 83 - 91 


\section{PENDAHULUAN}

Masa sekarang adalah masa yang penuh dengan persaingan di berbagai aspek dan bidang kehidupan, termasuk didalamnya bidang pekerjaan. Tidak terkecuali negara Indonesia yang memiliki jumlah penduduk yang besar sedangkan lapangan pekerjaan yang tersedia tidak sebanding dengan jumlah tenaga kerja. Hal tersebut membuat persaingan untuk mendapatkan pekerjaan menjadi sangat ketat menurut Handianto \& Johan dalam Daulay, S.F \& Fasti (2011)

Kesempatan untuk mendapatkan pekerjaan akan lebih mudah bila seorang pencari kerja mempunyai latar belakang pendidikan tinggi. Hal tersebut disebabkan karena melalui pendidikan, individu akan mampu meningkatkan kualitas sumber daya manusia. Oleh sebab itu seorang tenaga kerja harus menempuh pendidikan di perguruan tinggi atau universitas. Pendidikan tinggi yang berkualitas dengan hasil yang memuaskan sangat diharapkan oleh seluruh mahasiswa. Namun di zaman krisis seperti sekarang ini, biaya pendidikan sangatlah mahal sehingga hal tersebut memunculkan suatu fenomena yang berkembang, yaitu banyak mahasiswa yang kuliah sambil bekerja menurut Hadianto \& Johan dalam Daulay, S.F \& Fasti (2011).

Fenomena mengenai mahasiswa yang kuliah sambil bekerja juga ditemukan di Universitas Medan Area (UMA). Dari komunikasi interpersonal yang dilakukan dengan beberapa mahasiswa pada saat pra penelitian, diketahui tidak sedikit mahasiswa UMA yang kuliah sambil bekerja. Kuliah sambil bekerja banyak memberi dampak bagi mahasiswa baik positif maupun negatif. Dampak positifnya adalah dengan bekerja mahasiswa dapat membantu orangtua dalam membiayai kuliah, memperoleh pengalaman kerja serta kemandirian ekonomis (Motte \& Schwartz, 2009). Selain itu masalah yang perlu diwaspadai oleh mahasiswa yang bekerja adalah pekerjaan bisa membuat mahasiswa lalai akan tugas utamanya, yakni belajar (Yenni, 2007).

Menurut Ningsih (2009) Hal yang menjadi kendala dalam kuliah sambil bekerja yaitu tidak mudah membagi waktu antara kuliah, kerja, istirahat dan urusan-urusan lain. Mahasiswa yang memiliki kemampuan mengatur waktu yang baik dan memiliki batas waktu untuk setiap pengerjaan tugasnya adalah salah satu kriteria mahasiswa yang berhasil. Mahasiswa diharapkan mampu memakai rentang waktu dalam satu hari yaitu 24 jam itu dengan sebaik-baiknya untuk menyelesaikan tugas-tugas studinya sampai pada waktu pengumpulan tugas tersebut (Djamarah, 2002).

Agar sukses dalam pendidikan dan berhasil menerapkan ilmu yang diperolehnya, mahasiswa harus menggunakan seluruh potensi yang dimilikinya serta mengatur strategi belajar yang jitu. Salah satu keterampilan belajar yang mempunyai peran penting dalam menentukan kesuksesan diperguruan tinggi adalah kemampuan meregulasi diri dalam belajar atau disebut juga dengan self regulated learning.

Pentingnya self-regulated learning di perguruan tinggi baik itu pada mahasiswa yang bekerja sejalan dengan fenomena yang ditemukan di Fakultas 
Psikologi Universitas Medan Area melalui wawancara personal dengan salah satu mahasiswa semester tengah.

"Saya merasakan kuliah sambil bekerja membuat saya kurang mampu mengatur diri saya dalam proses belajar di kuliah dan juga dalam pengerjaan tugas yang diberikan dosen, sesudah pulang bekerja saya harus segera berangkat ke kampus dan itu membuat saya lelah sehingga ketika dikelas saya kurang bersemangat mengikuti pelajaran dan beberapa kali saya pernah tertidur didalam kelas. Kesulitan lain yang saya alami yaitu saya sulit mengatur waktu dalam pengerjaan tugas karena kesempatan belajar saya kurang sehingga dalam beberapa tugas saya memilih dikerjakan oleh orang lain kemudian saya mengupahi pengerjaan tugas itu tapi ketika waktu bekerja saya sedikit longgar saya sempat meluangkan waktu mengerjakannya sebentar walaupun lebih banyak orang lain yang mengerjakan tugas-tugas tersebut. Menurut saya memang sangat perlu adanya pengaturan dalam belajar apalagi sebagai mahasiswa yang bekerja agar bisa menyeimbangkan kemampuan dalam mengatur diri untuk bekerja maupun kuliah." (Komunikasi Personal, 26 November 2014).

Self regulated learning merupakan belajar mengatur diri sendiri, diantaranya adalah self generation dan pemantauan diri (self-monitoring) dalam berpikir, perasaan dan perilaku-perilaku untuk mencapai tujuan (Santrock, 2004). Self regulated learner adalah siswa yang secara metakognitif, motivasional dan behavioral merupakan peserta aktif dalam proses belajar mereka sendiri (Schunk, D.H \& Zimmerman, 1998). Beberapa penelitian menemukan bahwa siswa yang aktif mengelola dirinya dalam belajar cenderung memiliki prestasi yang lebih baik di bidang akademik. Salah satu karakteristik yang dimiliki siswa yang menggunakan self regulated learning adalah memiliki keaktifan dalam proses belajar dan memiliki kemampuan untuk mengatur belajarnya (Schunk, D.H \& Zimmerman, 1998).

(Schunk, D.H \& Zimmerman, 1998) menyatakan bahwa Self regulated learning adalah konsep mengenai bagaimana seorang peserta didik menjadi pengatur bagi belajarnya sendiri. Zimmerman menambahkan bahwa Self regulated learning merupakan sebuah proses dimana seorang peserta didik mengaktifkan dan mendorong kognisi (cognition), perilaku (behavior) dan perasaannya (affect) yang secara sistematis berorientasi pada pencapaian suatu tujuan belajar. Agar mencapai tujuan belajar tersebut, peseta didik yang menerapkan Self regulated learning mendekati tugas belajar dengan berbagai strategi manajemen sumber daya seperti memilih atau mengatur lingkungan fisik untuk mendukung belajar dan mengatur waktu mereka secara efektif.

Menurut Schunk, D.H \& Zimmerman (1998) menegaskan bahwa individu yang bisa dikatakan sebagai Self-regulated learners adalah individu yang secara metakognisi, motivasional dan behavioral aktif ikut serta dalam proses belajar mereka. Individu tersebut dengan sendirinya memulai usaha belajar mereka secara langsung untuk memperoleh pengetahuan dan keahlian yang mereka inginkan tanpa bergantung pada guru, orang tua, dan orang lain. 
Cobb (2003) menyatakan bahwa Self regulated learning dipengaruhi oleh banyak faktor, diantaranya adalah Self efficacy, motivasi dan tujuan. Menurut Cobb (2003) self efficacy, motivasi dan tujuan belajar yang dimiliki peserta didik secara positif berhubungan dengan Self regulated learning. Motivasi dibutuhkan peserta didik untuk melaksanakan strategi Self regulated learning yang akan mempengaruhi proses belajar. Peserta didik cenderung akan lebih efisien mengatur waktunya dan efektif dalam belajar apabila memiliki motivasi belajar. Peserta didik yang memiliki motivasi belajar akan memelihara keyakinan positif tentang kemampuan belajar (Self efficacy) dan meningkatkan penggunaan kognitif dan strategi Self regulated learning sedangkan tujuan (goal) merupakan kriteria yang digunakan peserta didik untuk memonitor kemajuan mereka dalam belajar.

Self-efficacy merupakan salah satu kemampuan pengaturan diri individu. Konsep self-efficacy pertama kali dikemukakan oleh Bandura. Self-efficacy mengacu pada persepsi tentang kemampuan individu untuk mengorganisasi dan mengimplementasi tindakan untuk menampilkan kecakapan tertentu (Bandura, 1997).

Self-efficacy membantu pengembangan bakat pendidikan dengan keterlibatan dalam kegiatan belajar. Melalui kegiatan ini, tingkat pencapaian dan motivasi biasanya meningkat dan berpengaruh positif (Zimmerman, 1989). Seorang mahasiswa dengan self-efficacy yang tinggi untuk suatu topik tertentu percaya pada kemampuan sendiri untuk menyelesaikan tugas, menemukan jawaban yang benar, mencapai tujuan, dan sering lebih unggul dibandingkan teman-temannya yang lain. Menurut Kohler dalam Daulay, S.F \& Fasti (2011), Self-effficacy bertujuan untuk memprediksi prestasi akademik, tetapi tidak kemampuan kognitif. Self efficacy dalam Self regulated learning mengacu pada kemampuan mahasiswa untuk menggunakan berbagai strategi Self regulated learning seperti pemantauan diri, evaluasi diri, penetapan tujuan dan perencanaan, konsekuensi diri, dan restrukturisasi. Self efficacy untuk Self regulated learning berhubungan secara positif dengan Self. Seseorang yang mempunyai Self efficacy tinggi maka Self regulated learning-nya juga tinggi. Begitupun sebaliknya, seseorang yang memiliki Self efficacy rendah, maka Self regulated learning- nya juga rendah.

Individu dengan self-effficacy yang tinggi untuk suatu topik tertentu percaya pada kemampuan sendiri untuk menyelesaikan tugas, menemukan jawaban yang benar, mencapai tujuan, dan sering lebih unggul dibandingkan teman-temannya yang lain. Ketika individu memiliki atau memelihara selfefficacy dalam pelajaran atau keterampilan tertentu, proses regulasi diri tercipta dan dipelihara (Pajares, F., \& Schunk, 2001)

Hal ini sejalan dengan hasil wawancara peneliti dengan seorang mahasiswa yang bekerja yang juga duduk di Fakultas Psikologi Universitas Medan Area yang diduga tidak menggunakan strategi self-regulated learning karena memiliki self-efficacy yang rendah. 
"Waktu awal-awal kuliah belum terasa kali banyak tugasnya. Tapi semester-semester selanjutnya mulai banyak tugas individu, kelompok, malah ada yang ke lapangan. Trus sering presentasi kelompok, bagi-bagi tugas, bikin makalah, slide, dan kuis juga ada. Saya merasa semakin banyak tugas semakin sulit menyelesaikannya karena gak yakin bisa ngerjain semua tu tugas sementara saya juga mesti kerja jadi lebih sering terbengkalai ngatur waktu belajarnya. (Komunikasi Personal, 24 November 2014).

Berdasarkan dari uraian latar belakang diatas, maka rumusan masalah dari penelitian ini adalah, Apakah ada "Hubungan antara Self efficacy dengan Self regulated learning pada mahasiswa yang bekerja"?

\section{METODE PENELITIAN}

Jenis penelitian yang digunakan adalah metode kuantitatif yang bersifat korelasional karena penelitian ini bertujuan untuk mengetahui hubungan antara self efficacy dengan self regulated pada mahasiswa yang bekerja.

Hipotesis dalam penelitian ini adalah "ada hubungan yang positif antara self efficacy dengan self regulated learning". Semakin tinggi self efficacy yang dimiliki mahasiswa yang bekerja maka semakin tinggi self regulated learning nya. Sebaliknya semakin rendah self efficacy yang dimiliki mahasiswa yang bekerja maka semakin rendah self regulated learning nya.

Teknik pengumpulan data dalam penelitian ini menggunakan teknik skala. Skala adalah suatu daftar yang berisi pernyataan yang diberikan kepada subjek agar dapat mengungkapkan aspek-aspek psikologis yang ingin diketahui.

Skala yang digunakan adalah skala Likert, yaitu skala yang menggunakan 4 (empat) alternatif. Penilaian yang diberikan kepada masing-masing jawaban subjek pada setiap pernyataan favourable adalah Sangat Setuju (SS) mendapat nilai 4, Setuju (S) mendapat nilai 3, Tidak Setuju (TS) mendapat nilai 2, dan Sangat Tidak Setuju (STS) mendapat nilai 1 . Untuk pernyataan yang bersifat unfavourable adalah Sangat Setuju (SS) mendapat nilai 1, Setuju (S) mendapat nilai 2, Tidak Setuju (TS) mendapat nilai 3, dan Sangat Tidak Setuju (STS) mendapat nilai 4.

Skala self efficacy disusun berdasarkan dimensi dari teori Bandura (1997) yang mengemukakan bahwa selfefficacy individu dapat dilihat dari tiga dimensi, seperti tabel 1 dibawah ini.

Tabel 1.

Skala Self Efficacy

\begin{tabular}{|c|c|}
\hline Aspek & Indikator \\
\hline $\begin{array}{l}\text { Tingkat } \\
\text { (level) }\end{array}$ & $\begin{array}{l}\text { Keyakinan individu atas } \\
\text { kemampuannya terhadap } \\
\text { tingkat kesulitan tugas. }\end{array}$ \\
\hline $\begin{array}{l}\text { Keluasan } \\
\text { (generality) }\end{array}$ & $\begin{array}{l}\text { Keyakinan individu akan } \\
\text { kemampuannya } \\
\text { melaksanakan tugas di } \\
\text { berbagai aktifitas. }\end{array}$ \\
\hline $\begin{array}{l}\text { Kekuatan } \\
\text { (strength) }\end{array}$ & $\begin{array}{l}\text { Tingkat kekuatan, keyakinan } \\
\text { atau kemantapan individu } \\
\text { terhadap kemampuannya. }\end{array}$ \\
\hline
\end{tabular}

Skala self regulated learning disusun berdasarkan aspek-aspek dari self regulated learning berdasarkan Schunk dan Zimmerman (1998), seperti tabel 2 dibawah ini:

Tabel 2

Self Regulated Learning

\begin{tabular}{cc}
\hline Aspek & \multicolumn{1}{c}{ Indikator } \\
\hline Metakognisi & Merencanakan; \\
\hline
\end{tabular}




\begin{tabular}{llr}
\hline & \multicolumn{2}{l}{ Mengorganisasikan atau } \\
& $\begin{array}{l}\text { mengatur; Megintruksikan diri, } \\
\text { memonitor; }\end{array}$ \\
& $\begin{array}{r}\text { Melakukan } \\
\text { evaluasi dalam } \\
\text { belajar. }\end{array}$ \\
\hline Motivasi & Pendorong yang ada di dalam \\
& diri individu dan merupakan \\
& kebutuhan dasar untuk \\
& mengontrol dan berkaitan \\
& dengan perasaan kompetensi \\
& yang dimiliki setiap individu. \\
\hline Upaya individu untuk & mengatur diri, menyeleksi, \\
& dan memanfaatkan \\
& lingkungan dan menciptakan \\
& lingkungan yang mendukung \\
& untuk belajar. \\
\hline
\end{tabular}

Alat ukur yang digunakan dalam penelitian selayaknya adalah alat ukur yang baik. Dimana alat ukur yang baik adalah alat ukur yang valid dan reliable.

Validitas adalah suatu ukuran yang menunjukkan tingkat-tingkat kevalidan ataun kesahihan sesuatu instrument. Suatu instrument yang valid atau sahih mempunyai validitas yang tinggi. Sebaliknya, instrument yang kurang valid berarti memiliki validitas rendah. Sebuah instrument dikatakan valid apabila mampu mengukur apa yang diinginkan. Sebuah instrument dikatakan valid apabila dapat megungkap data dari variable yang diteliti secara tepat (Arikunto, 2010).

Teknik yang digunakan untuk menguji validitas alat ukur penelitian ini adalah menggunakan rumus kolerasi yang dikemukakan oleh Pearson, yang dikenal dengan rumus korelasi Product Moment sebagai berikut:

$$
r_{x y}=\frac{\mathrm{N} \sum \mathrm{XY}-\left(\sum \mathrm{X}\right)\left(\sum \mathrm{Y}\right)}{\sqrt{\left\{\mathrm{N} \sum \mathrm{X}^{2}-\left\{\Sigma \mathrm{X}^{2}\right)\right\}\left\{\mathrm{N} \Sigma \mathrm{Y}^{2}-\left(\sum \mathrm{Y}^{2)}\right\}\right.}}
$$

Keterangan:

$$
\begin{array}{ll}
\mathrm{r}_{\mathrm{xy}} & =\text { Koefisien korelasi antara skor } \\
& \text { item dengan skor total } \\
\mathrm{N} & =\text { Banyaknya subjek } \\
\sum \mathrm{X} & =\text { Jumlah nilai aitem } \\
\sum \mathrm{Y} & =\text { Jumlah nilai total } \\
\sum \mathrm{XY} & =\text { Jumlah hasil kali antara skor } \\
& \text { item dan skor total } \\
\sum \mathrm{X}_{2} & =\text { Jumlah kuadrat skor item } \\
\sum \mathrm{Y}_{2} & =\text { Jumlah kuadrat skor total }
\end{array}
$$

Reliabilitas menunjuk pada satu pengertian bahwa satu pengertian bahwa sesuatu instrument cukup dapat dipercaya untuk digunakan sebagai alat pengumpul data karena instrument tersebut sudah baik. Reliabilitas menunjuk pada tingkat keterandalan sesuatu. Reliable artinya dapat dipercaya, jadi dapat diandalkan.

Pada penelitian ini menggunakan rumus Alpha untuk mencari reliabilitas instrumen yang skornya bukan 1 dan 0 , misalnya angket atau soal bentuk uraian. Dengan rumus sebagai berikut:

$$
\begin{aligned}
& r_{11}=\left(\frac{\mathrm{k}}{k-1}\right)\left(1-\frac{\sum \sigma_{\mathrm{b}} \mathrm{a}}{\sigma^{2} \mathrm{t}}\right) \\
& \text { Keterangan: } \\
& \mathrm{r} 11 \quad=\text { reliabilitas instrument } \\
& \mathrm{k} \quad=\text { banyaknya butir pertanyaan atau } \\
& \quad \text { banyaknya soal } \\
& \sum \sigma_{\mathrm{b}}^{2}=\text { jumlah varians butir } \\
& \sigma_{1}^{2} \quad=\text { varians total }
\end{aligned}
$$

\section{HASIL DAN PEMBAHASAN}

Teknik analisis data yang digunakan dalam penelitian adalah Analisis Korelasi Product Moment dari Pearson. Teknik analisis data ini digunakan dalam upaya mengungkap hubungan antara satu variabel bebas, yakni self efficacy, dan satu variabael terikat, yakni self regulated learning.

Namun sebelum data dianalisis untuk pengujian hipotesis, maka perlu dilakukan analisis uji asumsi yang 
meliputi uji normalitas dan uji linearitas hubungan. Uji asumsi harus terpenuhi agar analisis data untuk pengujian hipotesis dapat dilanjutkan.

Uji Normalitas sebaran ini adalah untuk membuktikan bahwa penyebaran data penelitian yang menjadi pusat perhatian, menyebar berdasarkan prinsip kurve normal. Uji normalitas sebaran dianalisis dengan menggunakan One Sampel Kolmogrov-Smirnov. Sebagai kriterianya apabila $\mathrm{p}>0,05$ maka sebarannya dinyatakan normal, sebaliknya apabila $\mathrm{p}<0,05$ sebarannya dinyatakan tidak normal (Hadi dan Pamardiningsih, 2000). Tabel berikut ini merupakan rangkuman hasil perhitungan uji normalitas sebaran.

Tabel 3

Rangkuman Hasil Perhitungan Uji Normalitas Sebaran

\begin{tabular}{lccccc}
\hline Variabel & $\begin{array}{c}\text { RERA } \\
\text { TA }\end{array}$ & SB & K-S & P & Keterangan \\
\multicolumn{1}{c}{$\begin{array}{c}\text { Self } \\
\text { regulated } \\
\text { learning }\end{array}$} & 94,298 & 15, & 0,119 & 0,00 & Normal \\
\hline Keterangan: & & 53 & & & \\
RERATA & 6 & & & \\
SB & $=$ & & \\
& $=$ & Silai rata-rata & \\
K-S & & (Standart Deviasi) \\
$\mathrm{p}$ & $=$ & Koefisien Kolmogrov-Smirnov \\
& $=$ & Peluang terjadinya kesalahan
\end{tabular}

Uji Linearitas Hubungan dimaksudkan untuk mengetahui derajat hubungan antara variabel bebas dengan variabel terikat. Artinya apakah self efficacy dapat mempengaruhi self regulated learning.

Berdasarkan uji linearitas, dapat diketahui apakah variabel bebas dengan variabel terikat dalam penelitian ini dapat atau tidak dianalisis secara korelasional. Hasil analisis menunjukkan bahwa antara variabel bebas self efficacy memiliki hubugan yang linear terhadap variabel terikat self regulated learning. Sebagai kriterianya apabila $\mathrm{p}<0,05$ maka dapat dinyatakan mempunyai derajat hubungan yang linear (Hadi dan Pamardiningsih, 2000). Nilai-nilai hubungan tersebut dapat dilihat pada tabel dibawah ini.

Tabel 4

Rangkuman Hasil Perhitungan Uji Linearitas Hubungan

\begin{tabular}{cccc}
\hline Korelasional & F Beda & $\begin{array}{c}\text { P } \\
\text { Beda }\end{array}$ & Keterangan \\
\hline $\mathrm{X}-\mathrm{Y}$ & 128,536 & 0,00 & Linear \\
\hline
\end{tabular}

\begin{tabular}{|c|c|}
\hline \multicolumn{2}{|c|}{ Keterangan: } \\
\hline $\mathrm{X}$ & $=$ Self Efficacy \\
\hline Y & $=$ Self Regulated Learning \\
\hline F Beda & = Koefisien linieritas \\
\hline P Beda & $=$ Proporsi peluang ralat \\
\hline
\end{tabular}

Berdasarkan hasil perhitungan analisis korelasi product moment, dapat diketahui bahwa terdapat hubungan positif yang signifikan antara self efficaccy dengan self regulated learning. Hasil ini dibuktikan dengan koefisien korelasi $r_{x y}=0,822 ; p<0,05$ Hasil ini mengartikan bahwa Semakin tinggi self efficacy maka semakin tinggi self regulated learning-nya, sebaliknya semakin rendah self efficacy maka semakin rendah self regulated learningnya. Dengan demikian maka hipotesis yang telah diajukan dalam penelitian ini dinyatakan diterima.

Koefisien determinan $\left(\mathrm{r}^{2}\right)$ dari hubungan diatas adalah sebesar $r^{2}=$ 0,675 Hal ini menunjukkan self regulated learning dipengaruhi sebesar 67, 5\%. Tabel berikut merupakan rangkuman hasil perhitungan $\mathrm{r}$ product moment

Tabel 5

Rangkuman Hasil Analisis Korelasi Product Moment

\begin{tabular}{|c|c|c|c|c|c|}
\hline Statistik & $\begin{array}{c}\text { Koefisien } \\
\left(\mathrm{r}_{\mathrm{xy}}\right)\end{array}$ & $\begin{array}{c}\text { Koef Det } \\
\left(\mathrm{r}^{2}\right)\end{array}$ & $\mathrm{P}$ & $\begin{array}{c}\mathrm{BE} \\
\%\end{array}$ & Ket \\
\hline $\mathrm{X}-\mathrm{Y}$ & 0,822 & 0,675 & 0,00 & 67,5 & Signifikan \\
\hline
\end{tabular}


Keterangan:

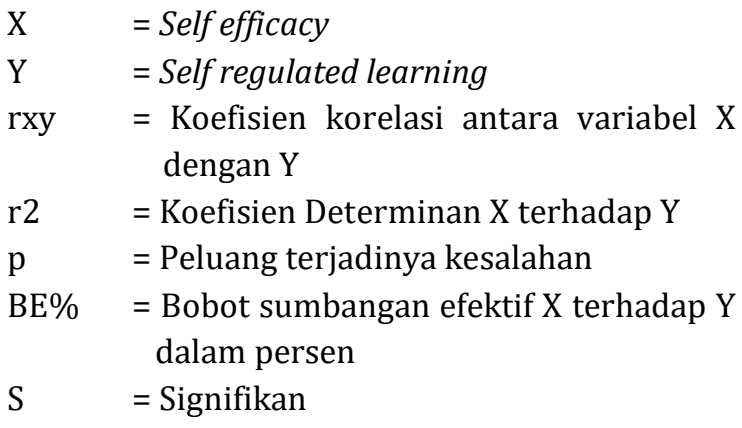

Jumlah butir pernyataan yang dipakai dalam mengungkap self efficacy adalah sebanyak 26 butir yang di format dengan skala likert dalam 4 pilihan jawaban, maka nilai rata-rata hipotetiknya adalah $\{(26 \times 1)+(26 \times 4)\}$ $: 2=65$.

Kemudian untuk variabel self regulated learning, jumlah butir yang dipakai adalah sebanyak 32 butir yang di format dengan skala likert dalam 4 jawaban, maka mean hipotetiknya adalah $\{(32 \times 1)+(32 \times 4)\}: 2=80$.

Berdasarkan analisis data, seperti yang terlihat dari analisis uji normalitas sebaran diketahui bahwa, nilai ratarata/mean empirik self efficacy adalah 77,865 sedangkan variabel self regulated learning, nilai rata-rata/mean empirik self regulated learning adalah 94,298.

Dalam upaya mengetahui bagaimana self efficacy dan self regulated learning, maka perlu dibandingkan antara mean/nilai rata-rata empirik dengan nilai mean/nilai rata-rata hipotetik dengan memperhatikan besarnya bilangan SB atau SD.

Untuk variabel self efficacy, bilangan satu SB atau SD adalah sebesar 13,738. Jadi apabila mean/nilai rata-rata hipotetik < mean/nilai rata-rata empirik, dimana selisihnya melebihi 13,738, maka dinyatakan bahwa self efficacy tergolong tinggi dan apabila mean/nilai rata-rata hipotetik > mean/nilai ratarata empirik, dimana selisihnya melebihi 13,738, maka dinyatakan bahwa self efficacy tergolong rendah. Apabila mean/nilai rata-rata empirik dan hipotetik tidak berselisih 13,738, maka self efficacy tergolong sedang.

Selanjutnya variabel self regulated learning, bilangan satu SB atau SD adalah sebesar 15,536. Jadi apabila mean/nilai rata-rata hipotetik < mean/nilai rata-rata empirik, dimana selisihnya melebihi 15,536, maka dinyatakan bahwa self regulated learning tergolong tinggi dan apabila mean/nilai rata-rata hipotetik > mean/nilai ratarata empirik, dimana selisihnya melebihi 15,536, maka dinyatakan bahwa self regulated learning tergolong rendah. Apabila mean/nilai rata-rata empirik dan hipotetik tidak berselisih 15,536, maka self regulated learning tergolong sedang.

Gambaran selengkapnya mengenai perbandingan mean/nilai rata-rata hipotetik dengan mean/nilai rata-rata empirik dapat dilihat pada tabel dibawah.

Tabel 6

Hasil Perhitungan Nilai Rata-rata

Hipotetik dan Nilai Rata-rata Empirik

\begin{tabular}{ccccc}
\hline Variabel & SD & \multicolumn{2}{c}{ Nilai Rata-Rata } & \multirow{2}{*}{ Ket. } \\
\cline { 3 - 4 } & & Hipotetik & Empirik & \\
\hline Self efficacy & 13,738 & 65 & 77,865 & Sedang \\
\hline $\begin{array}{c}\text { Self } \\
\text { regulated } \\
\text { learning }\end{array}$ & 15,536 & 80 & 94,298 & Sedang \\
\hline
\end{tabular}

Berdasarkan perbandingan kedua nilai rata-rata diatas (mean hipotetik dan mean empirik), dapat dinyatakan bahwa Self efficacy yang dimiliki mahasiswa yang bekerja tergolong sedang dan Self regulated learning yang 
dimiliki mahasiswa yang bekerja juga tergolong sedang.

\section{SIMPULAN}

Berdasarkan hasil-hasil yang telah diperoleh dalam penelitian ini, maka dapat disimpulkan bahwa terdapat hubungan positif yang sangat signifikan antara Self efficaccy dengan Self regulated learning. Hasil ini mengartikan bahwa Semakin tinggi self efficacy maka semakin tinggi self regulated learningnya, sebaliknya semakin rendah self efficacy maka semakin rendah self regulated learning-nya. Dengan demikian maka hipotesis yang telah diajukan dalam penelitian ini dinyatakan diterima.

Sumbangan yang diberikan oleh self efficacy terhadap self regulated learning adalah diatas rata-rata. Hal ini menunjukkan bahwa self regulated learning dipengaruhi oleh self efficacy.

Secara umum para mahasiswa yang bekerja di Universitas Medan Area memiliki self efficacy yang tergolong sedang dan self regulated learning yang juga tergolong sedang.

\section{DAFTAR PUSTAKA}

Arikunto, S. (2010). Prosedur Penelitian: suatu pendekatan praktik. Rineka Cipta.

Bandura, A. (1997). Self Efficacy: The Exercise of Control. Freeman and Company.

Cobb, R. (2003). The relationship between self regulated learning behaviors and academia performance in web-based course. Dissertation. Virginia Polytechnic Institute.

Daulay, S.F \& Fasti, R. (2011). Perbedaan self regulated learning antara mahasiswa yang bekerja dan yang tidak bekerja. Jurnal Psikologi.

Djamarah, S. . (2002). Bahasa Sukses Belajar. PT. Rineka Cipta.

Motte \& Schwartz, 2009. (2009). Are Students Employment and Academic Success
Linked?

Http://Www.Millenniumscholarships.Ca /.

Ningsih, A. R. (2009). Mungkinkah Mahasiswa Kuliah Sambil Kerja. Https://Www.Pikiran-Rakyat.Com/.

Pajares, F., \& Schunk, D. (2001). (2001). SelfBeliefs and School Success: Self-Efficacy, Self-Concept, and School Achievement. International Perspectives on Individual Differences: Self-Perception, 2.

Santrock, J. W. (2004). Psikologi Pendidikan (edisi kedu). Kencana.

Schunk, D.H \& Zimmerman, B. J. (1998). Self regulated learning from teaching to self reflection practice. The Guilford Press.

Yenni, D. (2007). Kuliah Sambil Kerja, Why Not. Medan Bisnis.

Zimmerman, B. J. (1989). A Social Cognitive View of Self Regulated Learning. Journal of Educational Psychology, 81. 